\title{
Article
}

\section{Blogs: A tool to facilitate reflection and community of practice in sports coaching?}

Stoszkowski, J., and Collins, D.

Available at http://clok.uclan.ac.uk/11664/

Stoszkowski, J., ORCID: 0000-0002-1968-5770 and Collins, D. ORCID: 00000002-7601-0454 (2014) Blogs: A tool to facilitate reflection and community of practice in sports coaching? International Sport Coaching Journal, 1 (3). pp. 139-151. ISSN 2328-918X

It is advisable to refer to the publisher's version if you intend to cite from the work. http://dx.doi.org/10.1123/iscj.2013-0030

For more information about UCLan's research in this area go to http://www.uclan.ac.uk/researchgroups/ and search for <name of research Group>.

For information about Research generally at UCLan please go to http://www.uclan.ac.uk/research/

All outputs in CLoK are protected by Intellectual Property Rights law, including Copyright law. Copyright, IPR and Moral Rights for the works on this site are retained by the individual authors and/or other copyright owners. Terms and conditions for use of this material are defined in the policies page.

\section{CLoK}

Central Lancashire online Knowledge www.clok.uclan.ac.uk

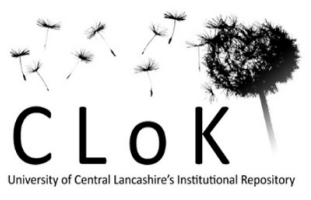


2 Blogs: A Tool to Facilitate Reflection and Community of Practice in Sports Coaching?

3 
Abstract

25 A reflective approach to practice is consistently espoused as a key tool for understanding and 26 enhancing coach learning and raising the vocational standards of coaches. As such, there is a

27 clear need for practical tools and processes that might facilitate the development and

28 measurement of "appropriate" reflective skills. The aim of this preliminary study was to

29 explore the use of online blogs as a tool to support reflection and community of practice in a cohort of undergraduate sports coaching students. Twenty-six students ( 6 females, 20 males) reflected on their coaching practice via blogs created specifically for reflection. Blogs were subjected to category and content analysis in order to identify the focus of entries and to determine both the emergent reflective quality of posts and the extent to which an online community of practice emerged. Findings revealed that descriptive reflection exceeded that of a critical nature, however, bloggers exhibited a positive trajectory toward higher order thinking and blogs were an effective platform for supporting tutor-student interaction. absence and an online community of practice did not emerge. 
An increasing body of research is focused on gaining a better understanding of how coaches develop their craft and learn how to coach (Nelson, Cushion, \& Potrac, 2006). Typically, this research has questioned the value, impact, and effectiveness of formal coach education programmes (cf. Cushion et al., 2010). Instead, the majority of coach learning has been shown to occur experientially through a wide and varied range of informal and selfdirected learning activities (Cushion, Armour, \& Jones, 2003; Lemyre, Trudel, \& DurandBush, 2007; Wright, Trudel, \& Culver, 2007). As a result, it has been argued that there is a need for innovative coach education approaches that can better equip coaches with the professional competencies needed to deal with the problematic and dynamic nature of their work (Morgan, Jones, Gilbourne, \& Llewellyn, 2013). For example, the language and value of reflection have become increasingly prominent in academic (and professional) coach education programmes. Indeed, a reflective approach to practice is now espoused as a key tool for understanding and enhancing coach learning and raising the vocational standards of coaches (e.g., Irwin, Hanton, \& Kerwin, 2004; Knowles, Gilbourne, Borrie, \& Neville, 2001; Lyle \& Cushion, 2010).

Nevertheless, due to a perceived lack of criticality and an over reliance on superficial and descriptive activities which are, in actual fact, inherently non-reflective as well as susceptible to a range of social influences, numerous authors have drawn attention to the inadequacy of the strategies often labeled as reflective practice in the sports coaching domain (e.g., Cropley \& Hanton, 2011). Although a number of authors offer structured guidance on the actual mechanics of reflection (e.g., Gibbs, 1988; Gilbert \& Trudel, 2001) and even on

71 how it may be taught (e.g., Gilbert \& Trudel, 2006), it has been suggested that current 72 reflective practice approaches often portray confusing agendas, with insufficient instructional guidance offered to coaches on "how" to engage in the process (Cropley, Miles, \& Peel, 
74 2012; Cushion et al., 2010) or indeed, on what aspects they should reflect (Abraham \&

75 Collins, 2011). As a result, Cropley and Hanton (2011) question whether the domain of

76 sports coaching has simply "jumped on the bandwagon" of reflection, without properly

77 considering and understanding the concept, and how it might be best implemented.

Within the literature, reflection is frequently depicted in a hierarchical representation

79 of distinct levels or stages of reflection, ranging from shallow description at one end to critical reflection at the other (e.g., Day, 1993; Hatton \& Smith, 1995; Sen \& Ford, 2009).

Crucially, it is the notion of critical reflection which is espoused as being the most

empowering and transformational in nature, allowing individuals to become more responsible for their actions and providing a basis for practice that is ultimately emancipatory (Black \& Plowright, 2010; Saylor, 1990; Sen \& Ford, 2009; Thompson \& Pascal, 2012). Critical reflection involves "looking beneath the surface" of a situation in order to identify and critique any assumptions that are being made, as well as challenge the values and beliefs that are being drawn upon (Mezirow, 1990; Saylor, 1990). Indeed, Thompson and Thompson (2008) highlight the importance of such critical "depth" in effectual reflective practice. However, they also stress the need for critical "breadth"; that is, the adoption of a wider lens in order to raise awareness of, and reduce susceptibility to, what Billet and Somerville (2004) term the "social press." Explicitly, this includes the historical, social, cultural, and institutional factors that influence and shape behavior (Jones, Armour, \& Potrac, 2002). As such, critically reflective coaches should be able to apply reflective processes that go beyond the descriptive and harness the "why" and "what for" of coaching practice. For example, we would expect them to (a) provide a critique of an incident or issue, not merely a description of what happened (Ghaye \& Ghaye, 1998); (b) step back and adopt a questioning approach when evaluating their experiences in order to understand "why" they coach the way they do (Cushion et al., 2003); (c) clarify and understand personal coaching philosophies and 
examine the underlying values and beliefs that shape their thinking and coaching practice (Jones et al., 2002); and (d) maintain an open mind and critically examine the values espoused by the social "milieu" and cultural context of their coaching practice (Stoszkowski \& Collins, 2012).

Nevertheless, in order to become critically reflective practitioners, coaches first need to "learn" the complex skill of reflection, which Knowles et al. (2001) caution "is not a simplistic process even with structured support" (p. 204). As such, there is a clear need for practical tools and processes that might facilitate the development and measurement of "appropriate" reflective skills. Accordingly, it is to one such potential tool that the focus of this paper now turns.

Traditionally, the most consistently heralded technique for promoting reflective practice in a variety of disciplines, including coaching, is structured written reflection, most commonly in the form of a reflective journal (Cropley, Miles, Hanton, \& Anderson, 2007;

Knowles et al., 2001; Moon, 2006). More recently however, a new wave of Web 2.0 technologies have emerged which provide alternatives to reflective journals and are said to have the potential to further strengthen and promote critical thinking and reflection in a range of learning environments (Boulton \& Hramiak, 2012). Web logs (known as blogs), are a social media platform that have been employed as a mechanism for increasing reflective capacity and facilitating deeper learning across a range of educational settings, including higher education (Churchill, 2009), teacher training (Stiler \& Philleo, 2003), internships (Chu, Chan, \& Tiwari, 2012), and medical education (Whitcomb, 2003). In its simplest form, a blog is an easily created website that resembles an online journal and allows an individual to frequently record and publish their personal thoughts, viewpoints, and reflections on the Internet (Downes, 2004; Sharma \& Xie, 2008). Posts are made using a web browser and are subsequently archived, organized, and displayed in reverse chronological order, allowing 
124 users to refer back to earlier entries. In addition to straight text and hyperlinks, blogs can also

125 incorporate other forms of media, such as images, audio, and video (Duffy \& Bruns, 2006).

126 As a result, a blog is said to be learner centered and full of authenticity, liveliness, and

127 accountability (Kang, Bonk, \& Kim, 2011). It has also been reported that blogs require no

128 additional technical knowledge than that needed for basic word processing (Cold, 2006), that

129 they are motivating learning activities in themselves (Pinkman, 2005), and that they promote

130 greater ownership of content than paper-based journals (Downes, 2004; Godwin-Jones,

131 2003).

132 Furthermore, and perhaps more interestingly, one notable promise of "blogging" is

133 that it promotes multi-layered social interaction and interpersonal communication by

134 enabling readers to comment on blog entries. That is, readers can provide feedback on the

135 ideas presented, as well as "prompt" further reflection and thought regarding a stated

136 viewpoint or opinion (Duffy \& Bruns, 2006; Top, Yukselturk, \& Inan, 2010). Similarly, a

137 number of authors have suggested that blogs provide the perfect platform for collaborative

138 learning and reflective conversation (Freeman \& Brett, 2012; Garrison \& Akyol, 2009;

139 Godwin-Jones, 2003). That is, students build knowledge together as they are responsible for

140 one another's learning as well as their own (Dooly, 2008). Consequently, blogs are said to

141 have the capacity to develop into effective online or "virtual" communities of practice (Hall,

142 2008; Killeavy \& Moloney, 2010). Wenger, McDermott, and Snyder (2002) defined

143 "communities of practice" as a group of people "who share a concern, a set of problems, or a

144 passion about a topic, and who deepen their knowledge and expertise in this area by

145 interacting on an ongoing basis" (p.4). In a CoP, each member is said to actively engage with

146 other members of the community (mutual engagement), actively share information and assist

147 each other to pursue the jointly agreed goal (joint enterprise), and share the routines, gestures, 
148 words and actions that are common to the CoP (shared repertoire) (Galipeau \& Trudel, 2006;

149 Wenger, 1988).

Moreover, shifting reflective journaling to an online medium such as a blog is said to

151 allow for "students" to have richer and more meaningful interaction with their tutors (Wolf,

152 2010). Tutors can observe and identify students' learning experiences, struggles, and

153 discomforts in order to make necessary accommodations during instructional activities

154 (Yang, 2009). Alongside this, they can assess the validity of the knowledge being generated during the reflective process. Comments on blog posts can then be used to provide frequent support in developing reflective skills as part of a formative process by accessing the blog

157 entries and sharing their expertise with the individual (Boulton \& Hramiak, 2012). Crucially,

158 blogs could therefore act as a platform to help coach educators direct and support experiential 159 learning (Culver \& Trudel, 2006) and provide coaches with the structures, issues, knowledge, and information they should reflect against, in order for their reflection to be sufficiently

161 critical. As such, the tutor's availability as an experienced dialogical other with which to 162 “do" reflection (Cushion, 2006) echoes Vygotsky's (1978) contention that an individual's 163 learning may be enhanced through engagement with a more capable other. Indeed, several authors have concluded that the ongoing support and leadership of a dedicated facilitator (i.e., tutor) is crucial if communities of practice are to work in sports coaching (e.g., Culver \&

166 Trudel, 2006; Culver, Trudel, \& Werthner, 2009). Despite a variety of authors advocating the use of blogging to promote reflective 168 practice (e.g., Bruster \& Petersen, 2013; Downes, 2004; Yang, 2009), the research available on the use of blogs in different educational activities remains relatively limited (Sharma \& 170 Xie, 2008). Furthermore, there remains a paucity of empirical research investigating their 171 application in the field of sports coaching. Indeed, at the time of writing, no published 172 studies have been undertaken which investigate the reflective affordances of blogs for coach 
173 development. It must also be noted that results in other fields often remain informal, unsystematic, and inconclusive (Kim, 2008; Sharma \& Xie, 2008). In addition, the general assumption that blogs can facilitate peer and group interaction, and, therefore, encourage the social construction of knowledge, are yet to be supported by empirical findings (Halic, Lee,

177 Paulus, \& Spence, 2010). Instead, it seems that the supposed technical advantages and 178 educational application of blogs have preceded evidence of their effectiveness (Halic et al., 2010; Tan, 2006). Therefore, the primary purpose of this preliminary investigation was to answer the

181

182 research question "Can blogs facilitate reflection and community of practice among a module cohort of sports coaching students?” In order to determine if participants could critically reflect on their coaching practice and participate in a community of practice (through the auspices of online blogs created specifically for reflection), three specific research questions served as guides in the data analysis:

1. What types of reflection were involved in students' blog posts, that is, were they descriptive or critical?

2. To what extent did blogs facilitate social interaction and the development of a community of practice?

3. What was the module tutor's role in the process of blogging?

\section{Method}

\section{Participants}

The sample in the present study consisted of 26 full-time undergraduate students (6 females and 20 males), who made up a module cohort on a Sports Coaching degree program during the 2012/13 academic cycle. The average age of the participants was 20.04 years (SD $=1.34$ ) and the median coaching experience was reported as 2 years, with experience ranging from 1 to 5 years in a range of sports (See Table 1). All participants were concurrently 
198 coaching in the community (i.e., over and above any practical coaching associated with their course of study) for a minimum of two hours per week and had completed at least one national governing body coaching award, with the highest awarded qualification translating to level two of the UK coaching certificate endorsed framework (Sports Coach UK, 2012a).

202 Two participants had previous experiences with blogging.

\section{Procedure}

The module in question was titled "The Reflective Coach" and was a compulsory component of the second academic year of the degree program. At the same time, students were undertaking five other modules, two of which were compulsory and specifically related to the pedagogy of coaching and professional practice. Their remaining three modules were option choices selected from a suite including sports science and the "ologies" of coaching (e.g., sport psychology etc.), and the development and sociology of sport (e.g., community sport development, talent development pathways etc.). An introductory lecture highlighted the module's aims, learning outcomes, and assessment procedures. Students were advised

212 that the upkeep of an ongoing reflective blog was a necessary element of assessment (worth $21360 \%$ of final module grade) and were instructed to set up their own blog using the externally hosted blog service of either https://wordpress.com or https://blogger.com. It was explained that they could customize the web address of their blog, select a design template, and make other layout customizations; as such, it was made clear that the ownership of the blogs lay

217 with the user (Tan, 2006). The second week's session was split into two. The first half 218 explored the conceptual and practical issues associated with reflective practice. Here, Gilbert 219 and Trudel's (2001) structured model of experiential learning, which has gained credence in 220 the extant literature (Cushion et al., 2010), was presented as an exemplar framework to guide 221 the reflective process. The second half then focused on reflective blogging; its purpose, 222 process, and pedagogical value. At the end of the session, students were given a reading list 
223 of academic literature pertaining to reflective practice and instructed to make the first post on

224 their blog. The third week was then given over to the logistical procedures of the blogging

225 assessment. The module tutor explained that there was no length or subject requirement for

226 posts, but students were asked to reflect on personally significant events or "critical

227 incidents" (Cropley \& Hanton, 2011; Holt \& Strean, 2001) during their coaching/learning

228 (both inside and outside of university). It was explained that unlike most academic writing,

229 which is commonly in the third person, the use of first person was encouraged in order to

230 promote ownership and personalization of the entries (Moon, 2006). Based on the

231 assessment marking criteria, students were advised of the requirement to contribute to their

232 blogs regularly for the remainder of the academic year (26 weeks). This was stipulated as a

233 minimum of 15 separate posts made in different weeks. Other criteria included the quality of

234 written expression, level of reflection, analysis of material in relation to appropriate

235 theoretical concepts/models, and citations/links to additional relevant material (i.e.,

236 appropriate academic literature). Finally, in order to encourage the emergence of a

237 community of reflective practice, students were asked to read and provide constructive

238 feedback on their peers' blogs for the remainder of the module by clicking on the "reply" or

239 "comment" link on selected entries. As such, students were asked to maintain privacy

240 settings that would allow their blog to be openly viewed by their peers. In addition, it was

241 explained that the module tutor would monitor blog posts and provide regular feedback via

242 the same process.

243 Timetabled sessions for the remainder of the module (2 hours per week) primarily

244 involved student-led practical workshops designed to explore pedagogical theories and

245 concepts relating to coaching practice. Additional tutor support and feedback on blog entries

246 was also provided during one-to-one tutorials each semester, as well as during casual

247 discussions within timetabled sessions. The tutor recorded thoughts emerging from these 
248 feedback processes and other observations of blogging activity in field notes for the full 249 duration of the module.

\section{Data Analysis}

A category analysis of all students' blog posts was conducted in order to identify the

252 focus of the entries they had made and determine the reflective quality of the writing

253 exhibited. First, each post was read multiple times and coded according to categories based on Yang's (2009) framework for qualitative research on reflective blogs. As Yang's (2009) framework focused on trainee teachers' reflections on the teaching process, it was modified to fit the aims of the present study, which resulted in the following categories and subcategories:

1. Theories of coaching. Postings by the students about the pedagogical theories relating to coaching practice taught on the course.

2. Own coaching practice. Postings by the students referring to their own coaching practice and the approaches and methods employed, as well as their expression of beliefs and knowledge related to these practices.

3. Others' coaching practice. Postings relating to the coaching practice of others and the approaches and methods utilised, as well as their expression of beliefs and knowledge related to these practices.

4. Self-awareness. Postings based on self-consciousness and self-evaluation of own skills and knowledge.

5. Blogging. Postings about; (a) the use of the blog, and (b) interacting with others online.

270 During this analysis, a single blog post could fit into more than one category. On the two

271 occasions where the authors, both of whom were experienced researchers in qualitative

272 methods, disagreed about the categories in which a post was placed, negotiation was pursued 
273 until a consensus of opinion was reached on their accuracy and clarity. Following the recommendations of Krane, Andersen, and Strean (1997), a reliability check was also conducted by asking an independent investigator, trained in qualitative methodology but blind to the objectives of the study, to audit the assigned categories to ensure that they 277 accurately reflected blog entries. No errors were found. reflective writing framework, which has been used previously to identify levels of reflection in student writing (Boud \& Walker, 1998; Moon, 2006; Whipp, 2003). Hatton and Smith (1995) based this framework on an extensive literature review and refined the categories and definitions it employs over several trials (Rourke \& Anderson, 2004). They identify four types of writing: unreflective descriptive writing, descriptive reflection, dialogic reflection, and critical reflection. To support reliability when coding, Hatton and Smith (1995) provide detailed guidance for using the framework, including specific examples for each of the four categories (Poom-Valickis \& Mathews, 2013). They also advise that within a single unit of writing (i.e., a blog post) students may employ a lower level of reflection in order to then progress to a higher level of reflective writing. As a result, each blog post was coded according to the highest level of reflection reached within that entry (Freeman \& Brett, 2012). Again, on the very few occasions (three) where minor coding discrepancies emerged between the two authors, negotiation was pursued until a consensus of opinion was reached. Finally, content analysis was used to examine each blog in terms of the number of entries, the frequency of posts, the number of posts incorporating citations to other relevant material, and the word count of each entry. Following the research methodology of Kol and Schcolnik (2008), each blog was also examined using a web-based text analysis tool

296 (http://textalyser.net/) in order to identify possible differences in lexical density (i.e., the 297 complexity of posts) between semester one and two. This analysis was also applied in order 
to identify changes in the range of vocabulary used in blogs (i.e., the number of different words).

\section{Results}

A total of 448 blog entries were analysed (217 in semester one, 231 in semester two),

302 including 433 written posts and 15 containing speech based audio which were transcribed

303 verbatim and coded. The total number of blog entries made by each student ranged from 10 to $31(M=17.23, S D=4.51)$, with written posts ranging from a minimum of 81 to a maximum of 2481 words in length $(M=518.35, M d n=428, S D=323.65)$, and audio posts ranging from a minimum of 46 seconds to a maximum of 204 seconds $(M=100.87, M d n=$ $76, S D=54.01)$. The focus of students' blog posts varied. Table 2 shows that students' own coaching practice was the most frequent topic, followed by self-awareness of their own skills and knowledge, and posts relating to the theories of coaching taught on the course. The least frequent topic was the process of blogging itself. The findings of the present study are now arranged by the three research questions presented earlier in this paper.

\section{What types of reflection were involved in students' blog posts?}

As Table 3 shows, $11.16 \%$ of blog posts were coded as unreflective descriptive writing according to Hatton and Smith's (1995) criteria. In these cases, the students simply described what had happened and how they had responded to an incident or situation.

316 Beyond this, there was no discussion or analysis of the issue. For example, "The majority of 317 the children engaged very well...However, there were one or two children in my group who 318 just weren't interested in taking part and despite my best efforts, I couldn't get one of the 319 children to take part." With regard to more "productive" posts, the largest proportion of 320 coded units $(56.47 \%)$ constituted descriptive reflection. These posts also involved students

321 providing an outline of what had happened and how they had responded to a situation or 322 incident from their own perspective. Notably however, they also evidenced attempts to give 
323 reasons or provide justifications for events or actions. Nevertheless, this was again reported

324 or described in an uncritical way, as stated in Hatton and Smith's (1995) criteria. For example, "The tone of my voice at times can be too low and I can at times speak too quickly when nervous. This is most common when I work alone as I can become nervous if I feel

327 pressured." The second largest proportion of students' blog posts (29.91\%) were coded as dialogic reflection. As defined, this type of reflection is more analytical, and involves stepping back from, mulling over, or tentatively exploring reasons for events, for example: It's really weird how much more confident I feel around this group than the coaching group at Uni. I think it could be because I'm not afraid to do something wrong whereas in class I'm afraid of doing something wrong and looking stupid. In addition to description and analysis of the problem, the blog posts classified as dialogic reflection also evidenced attempts to report an understanding of the wider context and see things from alternative points of view, for example: Why doesn't this type of session happen more often in schools? They learn transferable skills, which you can see improving in front of you as they get more tries at their game...I taught football in their school last year and I never saw the kids be as involved, keen or inventive as I saw them today.

341 Crucially, only $2.45 \%$ of blog posts corresponded to Hatton and Smith's (1995) criteria for 342 critical reflection. As defined, this type of reflection demonstrates an awareness that actions 343 and events are not only explicable by multiple perspectives, but are also located in and 344 influenced by multiple historical, cultural, and socio-political contexts. For example, "As a 345 developing coach, and having had experience of teaching within a secondary school, 346 inclusion is a major aspect of the delivery process that is being pressed." Or, for example, 347 "Sometimes I think that coaches can become entangled in the success and publicity side of 
348 competition. We rarely challenge the purpose of the competition or the impact it has on children's development..."

Table 1 shows that 12 students posted on their blog 15 times (or less) during the year,

351 the basic requirement for the module, suggesting minimal engagements in the process. Of

352 those 12 participants, only six increased their number of posts between semester one and

353 semester two, and 10 increased the quality of their reflection (see Table 1). Of the 14 other

354 participants, six increased their number of posts and 13 increased the quality of their

355 reflection. In sum, only twelve of the 26 participants increased their number of posts, but 23

356 demonstrated evidence of the development of a more reflective style and a clear difference in

357 the reflective quality of their entries between the two semesters. Indeed, Table 3 shows that

358 the number of posts coded as dialogic and critical reflection rose in semester two when

359 compared to semester one. At the same time, the number of posts coded as descriptive

360 writing and descriptive reflection fell during the same period. Similarly, during semester

361 two, only one participant did not have dialogic or critical reflections, compared to 11

362 participants in semester one (see Table 1). Nevertheless, it seems that reaching the dialogic

363 and critical reflection levels was difficult for many of the participants since half of them had,

364 after two semesters, three or less of their posts at the level of dialogical or critical reflection.

365 Interestingly, of the very few posts that were made using uploaded audio, 12 of the 15 were

366 coded as dialogic reflection and the remaining three as descriptive reflection.

367 Positively, the number of blog posts that integrated citations to appropriate theoretical

368 concepts and academic literature within the discussion rose from an average of 3.88 per

369 student blog in semester one to 5.08 per blog in semester two. Similarly, Table 2 shows that

370 the number of blog posts that focused (at least partly) on the theories of coaching covered in

371 class increased between the two semesters. This suggests that some students began to make

372 more consistent links between theory and coaching practice, which would be expected with 
373 the development of less descriptive reflection. This was coupled with a rise in the average

374 length of posts from 498 words in semester one, to 536 words in semester two, and a rise in

375 the average number of different words used in student blogs from an average of 891 different

376 words used in semester one to 1022 different words used in semester two. This is considered

377 an indication of development in the expression and elaboration of thoughts between the two

378 semesters. In addition, 19 out of the 26 students showed a reduction in the lexical density of

379 posts made in semester two when compared to semester one. This suggests that blog entries

380 became less complex and more easily understood as students used terminology surrounding

381 core concepts more consistently.

382 To what extent did blogs facilitate social interaction and the development of a

383 community of practice?

$384 \quad$ At the start of the module, three students stated their reluctance to make their blog

385 posts accessible for peer viewing and did not configure their privacy settings to permit this

386 until half way through semester one. Of the 26 students that maintained blogs during the

387 module, none provided direct feedback by leaving comments on the blog posts of their peers.

388 Similarly, none of the 448 entries made were aimed directly at the blogging environment and 389 creating a sense of community. Despite this, it was clear when surveying the students' blogs

390 that they were making a conscious effort to read their peer's blogs. For example, this was

391 evidenced in comments such as "One blog I looked at showed particular success from the

392 blog style of reflection, this blog talks about their resistance to begin blogging but once the

393 routine of posting was established they found it a useful tool for reflection." And, for

394 example, "Reading through peoples' blogs; it's clear that confidence, or lack of, is one of the

395 key concerns that a lot of people are focusing on improving throughout the year."

396 Similarly, several students made regular reference to their peer's blogs within their

397 own blog posts, indeed, often including direct links and "reflecting" on what they had read. 
398 For example, one student remarked “...after reading X's thoughts on this session

399 (click here to view his post) it's interesting to see that he noticed our position when giving instructions to the kids, this is something I was not aware of..." Whilst another commented: I don't agree with X's further comments about me being the favored coach...He says it's because I get across information in a sneaky way. By this I think he means that I probe and probe until they really show an understanding.

\section{What was the module tutor's role in the process of blogging?}

Getting five students "signed up" with their personal blog account took more time

than anticipated and the module tutor spent several weeks prompting these students to do this

407 through direct emails. The tutor read all student blogs and provided feedback,

408 encouragement, and questioning to students via the "comment" function on each entry. For example, "Well done, X. There is more depth coming through in this post...you are starting to get down into the "why' and 'how' which is good." And, for example, "Very insightful post, Y. It would have been good to see a little more literature on reflective practice to help

412 back up these points but you make links with your own practice well." In many cases, the 413 tutor's feedback stimulated additional reflection, evidenced in subsequent "reply" comments 414 by the student, for example: Thanks for the comment! I do have a tendency of being too descriptive...I have been trying to add more analytical thinking. I really appreciate your help as this is something I struggle with, is there anywhere you would suggest I could go to develop

419 In addition, the feedback left by the module tutor would often prompt informal discussion with the student during timetabled sessions and tutorials. On these occasions, students would

421 often ask for clarification on the comments made, or reaction to the subsequent posts made 422 after tutor feedback. In addition, the tutor would, at times, attempt to encourage students to 
423 read the posts of others in order to stimulate further reflection. For example, “...this post

424 (hyperlink inserted) on a similar theme might stimulate some thought, do you agree with the 425 author?"

On each blog, the posts were dated and timed for the entry or upload of material. If a

427 student had not posted to their blog for more than three weeks (13 instances), the module

428 tutor would highlight this via comments on the blog, prompts "in person" and direct email.

429 As a result, some students would "bulk" upload the equivalent of several weeks of entries at

430 one time. When enquiring as to the reason for this, the tutor was often told that students

431 preferred to construct posts in a word processed document in order to later "cut and paste"

432 onto their blog, as opposed to composing posts directly on the blog itself.

433

435

436

437

438

\section{Discussion}

The findings of the present study are now discussed in line with the three research questions presented earlier in this paper.

\section{What types of reflection were involved in students' blog posts?}

Consistent with the findings of other studies on the use of blogs for reflection (e.g., Lucas \& Fleming, 2012; Parkes \& Kajder, 2010; Yang, 2009), results highlighted that both descriptive and critical reflection was evidenced in students' blogs, with the number of descriptive reflections far exceeding those of a critical nature. Encouragingly, the majority of students exhibited a positive trajectory toward higher order thinking, giving weight to the suggestion that blogs might be a useful tool to foster the development of reflection in sports coaching. However, in line with other attempts to formally integrate coach reflection into university based coach education courses (e.g., Jones \& Turner, 2006; Knowles, Tyler, Gilbourne, \& Eubank, 2006), some students struggled to adopt a reflective practice orientation. That is, they did not move beyond sporadic use of their blog and reach the dialogic and critical reflection levels on a regular basis (see Table 1). As such, it is clear that 
448 the mere provision of a reflective tool is no guarantee that those using it will automatically

449 reflect at higher levels (Hatton \& Smith, 1995). The results also lend weight to earlier contentions that critical reflection is a skill that should be taught rather than assumed (Gilbert

$451 \&$ Trudel, 2006).

452 It has been suggested that coaches find it difficult to engage in effective reflection 453 unless they have the underpinning theoretical knowledge the reflective process requires (Peel, 454 Cropley, Hanton, \& Fleming, 2013). As such, we recognize that whilst the participants in the 455 present study were given instructional guidance on how to reflect on their coaching practice using blogs, with Gilbert and Trudel's (2001) structured model of experiential learning

457 presented as a potential framework to guide the reflective process, this could have been 458 insufficient to allow them to develop their understanding of the purposes and process of 459 reflective practice. That is, although the introductory lectures in the present study provided 460 participants with a structure to guide the mechanics of reflection, the actual reflective process 461 of issue setting, unpacking, and solving was not operationalized fully (Abraham \& Collins, 462 2011). For example, participants were not encouraged to critically examine and analyze their 463 role frames in order to identify and/or reduce potential biases that might otherwise have 464 guided or influenced their behavior (Gilbert \& Trudel, 2004). Equally, whilst having sports 465 coaches reflect on their day-today learning experiences in their own coaching context is 466 important (Gilbert, Gallimore, \& Trudel, 2009), we recognize that by specifically asking 467 participants in the present study to focus on "critical incidents" during their experiential 468 learning, they may have been overly concerned with identifying or focusing on negative 469 aspects, or perceived "problems" within their coaching practice (Dixon, Lee, \& Ghaye, 470 2013). In this regard, Smith and Jack (2005) suggest that individuals may "search" for 471 problems on uneventful days in order to tick the assessment box, whilst Dixon et al. (2013) 
472 propose that coaches might neglect to focus on their strengths and "how" they do what they 473 already do well.

474 Clearly then, if we are to utilize blogs to facilitate reflection in coach education, we

475 may first need to put more explicit processes and strategies in place to both encourage

476 participation and guide coaches toward higher levels of reflection (Peel et al., 2013). Indeed,

477 the absence of sufficient structures to support reflective practice has been cited as an inhibitor

478 of enhanced reflection in previous research (Larrivee, 2008; Otienoh, 2009), with Knowles,

479 Borrie, and Telfer (2005) finding that none of the coach education programmes they

480 examined contained processes to overtly nurture reflective skills. Accordingly, Gilbert and

481 Trudel (2013) suggest that support devices such as reflection cards and critical reflection

482 exercises might help coaches to reflect more critically on their learning. Similarly, it has

483 been suggested that detailed rubrics or matrixes of descriptors characterizing reflections

484 might promote the development of critical reflection (Fernsten \& Fernsten, 2005; Larrivee,

485 2008), whilst structured blogging "tasks" (e.g., instructor prescribed topics), have been said

486 to lead to more focused and specific blogging without detracting from the personalized nature

487 of content (Robertson, 2011). Nevertheless, it is important to remember that the development

488 of reflective capacity is a complex process requiring time, effort and practice in order for it to

489 be "learned" (Gelter, 2003; Knowles et al., 2001). Consequently, it must be noted that

490 although the present study required participants to reflect using their blog for a period of 26

491 weeks, this timeframe might still be insufficient to engender familiarity with, and

492 commitment to, the medium of blogging and the development of critically reflective skills

493 (Cropley et al., 2012).

494 To what extent did blogs facilitate social interaction and the development of a

495 community of practice? 
The "social" influence of the blogging process was another factor which may require explicit development. Despite several researchers (e.g., Boulton \& Hramiak, 2012; Hall, 2008; Hara \& Hew, 2007; Yang, 2009) reporting that blogs have the capacity to promote social interaction and the development of virtual learning communities, and a significant 500 body of research suggesting that coaches learn through their social interactions with others 501 (e.g., Culver \& Trudel, 2006; Erickson, Bruner, Macdonald, \& Côté, 2008), the present study found that participants did not take advantage of the collaborative and peer discourse features of blogs. Although students had direct access to peers' blogs (Wenger, 1998), and it was 504 apparent that many of them made the effort to regularly read their peers' blog posts, overt 505 dialogue and "reflective conversation" (Cropley et al., 2012) in the form of comments was 506 conspicuous in its absence. As such, it is clear that a community of practice was not an 507 automatic consequence of the availability of a collaborative tool in the present study (Chan \& Ridgway, 2006). This finding echoes the assertions of other researchers who have reported that participants can often find it difficult to "make the step" toward a stronger sense of 510 community in an online environment (e.g., Killeavy \& Moloney, 2010). Similarly, more 511 dedicated "offline" studies have struggled to get coaches to interact with their peers and engage in the joint enterprise that characterizes a functioning CoP (Culver \& Trudel, 2006,

513 Culver et al., 2009; Trudel \& Gilbert, 2004). For example, Gilbert and Trudel (2005) suggest 514 that, whilst having access to peer sounding boards is vital, the mere availability of peers is 515 not enough. Furthermore, those peers must also be respected and trusted for their knowledge 516 of coaching before coaches will seek their counsel. Crucially however, Mallett, Rossi, and 517 Tinning (2007) propose that the mutual trust and respect required to encourage social 518 interaction between coaches can take many years to develop, something that the participants 519 in the present study had not had. In addition, Lemyre et al. (2007) propose that facilitative 520 peer interaction between coaches is never inevitable, as the "tradition" in coaching is not for 
521 coaches to share knowledge, but to conceal ideas in order to gain a competitive advantage. In 522 short, both this literature and our findings question the view of communities of practice as a 523 panacea in the coach development process, as apparent in the relative uncritical initiation and 524 rapid promotion of such groups, without the clearly essential carefully staged evolution. 525 Importantly however, Romiszowski and Mason (2004) argue that a seldom-

526 challenged assumption exists in online learning research whereby a lack of overt dialogue is 527 perceived as learners being "passive recipients" as opposed to actively engaged in learning 528 with others. In fact, Wenger (1998) suggests that the social construction of meaning does not 529 always require others to be "present." It could be argued, therefore, that the participants in 530 the present study were still capable of learning more from "lurking" (cf. Wright et al., 2007) 531 and "just" reading the reflections posted by their peers than if they had simply recorded their own personal reflections (Boulton \& Hramiak, 2012). This is perhaps similar to the assertions of a range of authors, who suggest that apprentice coaches spend time simply

534 observing other coaches as they become socialized into a subculture and learn how things 535 should be done (Lemyre et al., 2007; Nash \& Sproule, 2009; Stephenson \& Jowett, 2009).

536 Crucially then, we must acknowledge that the extent of the social interaction between the participants in the present study may have been assessed by potentially insufficient or overly 538 simplistic quantitative measures, that is, the number of comments students made on peers' 539 blogs (Hrastinski, 2009).

540 Nevertheless, to facilitate and encourage interaction between students and the 541 purposeful discourse characteristic of collaborative learning and the co-construction of 542 knowledge (Chan \& Ridgeway, 2006; Garrison \& Akyol, 2009), more specific guidance on 543 both the process and value of peer-to-peer learning may have been needed. For example, 544 Gilbert et al. (2009) suggest that a written protocol describing how coaches should operate in 545 peer learning settings would increase the accountability of coaches in such a learning 
546 environment. Crucially, it must also be noted that previous studies that report significant

547 levels of peer interaction and discussion on blogs required learners to complete directed tasks

548 (e.g., Yang, 2009). Additionally, we recognize that the reflective affordances of the

549 individual blogs operationalized in the present study might be insufficient for promoting the

550 social discourse necessary for collaborative reflection. For example, group blogging,

551 whereby a single blog functions as a collective platform for a "small" group of people to

552 contribute and simultaneously share learning experiences, is said to support the emergence of

553 interactive online communities and collaborative reflection (e.g., Makri \& Kynigos, 2007).

554 This communal deliberation is subsequently said to encourage each individual group member

555 to become more critically reflective (Jarvis, Holford, \& Griffin, 2005). Consequently, group

556 based blogging might align more closely with social constructivist perspectives on learning

557 (e.g., Vygotsky, 1978; Wenger, 1998), which many authors draw upon to stress the

558 importance of dialogue with others in providing a "place" for the development of reflective

559 practice and learning (Boulton \& Hramiak, 2012; Reingold, Rimor, \& Kalay, 2008). As

560 such, the adoption of reflective group blogs as a more overt means of establishing online

561 communities of practice is an interesting area for further investigation within sports coaching.

\section{What was the module tutor's role in the process of blogging?}

563 Attempts to systematically integrate reflection into coach education programmes have

564 primarily focused on reflection that is socially supported and/or mediated (Gallimore, Gilbert,

$565 \&$ Nater, 2013), with a trained "facilitator" who leads and supports the process said to be key

566 (Cassidy, Potrac, \& McKenzie, 2006; Lyle, 2002). Collectively, the results in the present

567 study indicate that blogs were an effective platform for the module tutor to instigate and

568 facilitate meaningful dialogue with students in order to support their experiential learning and

569 guide the reflective process where necessary (Culver \& Trudel, 2006). Crucially however,

570 this was only the case with those students who fully engaged in and committed to the 
571 blogging process; a factor which must be considered and catered for both in future studies

572

573

574

575

576

577

578

579

580

581

582

583

584

585

586

587

588

589

590

591

592

593

594

595 and practical applications.

Such issues notwithstanding, the tutor was able to offer guidance on what elements of a coaching issue need to be attended to, suggest what additional knowledge might be required, and propose strategies that the coach might use to address the issue (Abraham \& Collins, 2011). Significantly, existing research has emphasized the importance of this type of intervention if reflection is to move beyond the basic level of description (Churchill, 2009). For example, significant empirical support has emerged for the scaffolding of reflection through appropriate questioning from a mentor or more capable other (e.g., Reingold et al., 2008; Vygotsky, 1978; Whipp, 2003).

However, in retrospect, the tutor recognized that his questioning comments could have been in and of themselves more critical in order to draw out and encourage higher levels of reflective thinking in the students. For example, when commenting on blog posts, the tutor tended to encourage students to become more aware of their behaviors and develop a rationale for their behavior by utilizing “why?" and "what if?” questions (Cushion et al., 2003; Lyle, 2002). Yet, he rarely prompted students to be more aware of their role frames (Gilbert \& Trudel, 2004) and the values and beliefs that might underpin their behavior in a particular situation (Jones et al., 2002). Moreover, little reference was made to the social and cultural context of students' practice, all factors inherent within critical reflection. This is particularly important, if, for example, we consider the social environment in which a coach works. This environment is extremely complex, and coaches are faced with a diverse range of influences, which pressure them to behave in certain ways in order to conform and secure approval (Bowes \& Jones, 2006; Collins, Abraham, \& Collins, 2012; Stoszkowski \& Collins, 2012). Consequently, the subtleties of this environment can promote and perpetuate the value and acceptance of certain types of knowledge and behaviour over others (Cushion et 
596 al., 2003) and guide what coaches choose to pay attention to as well as what they choose to 597 learn (Werthner \& Trudel, 2006). However, when considering the relative inexperience of 598 some participants, the module tutor felt this level of questioning was perhaps beyond their 599 current level of understanding. Indeed, several authors attribute the superficial nature of

600 novice practitioners' reflections to less developed schema and a lack of appropriate 601 theoretical knowledge due to insufficient experience (Moon, 2006; Tan, 2006). This raises 602 the question of when is the appropriate time for this to occur and whether the journey toward 603 critically reflective practice is a linear journey through the distinct and progressive stages of 604 reflection.

\section{Conclusion}

Generally, results indicate that blogs hold the potential to facilitate reflection in coaches; however, in the present study they did not facilitate overt collaborative learning and the emergence of a community of practice. Nevertheless, we believe enough promise exists to warrant further investigation of their potential in coach education pedagogy (Morgan et al.,

610 2013), particularly in utilizing group blogs to provide coaches with the opportunity to 611 enhance critical thinking skills by engaging in peer dialogue and collaborative reflection 612 (Culver \& Trudel, 2006; Dixon et al., 2013; Manouchehri, 2002). Promisingly, given that a 613 recent four-year coach tracking study found that the cost, timing, and travel involved in 614 accessing coach education are major barriers to uptake (Sports Coach UK, 2012b), it seems 615 Web 2.0 platforms such as blogs could allow coach educators to provide ongoing support to 616 those coaches undertaking certification courses at relatively little monetary and "time" 617 expense to both parties when compared to face-to-face solutions (Piggott, 2013).

618 As with prior research into the use of blogs in learning however, several

619 methodological issues remain and we recognize the limits of what can be accomplished by a 620 relatively small scale and short-term study of this nature. For example, as the current study 
621 utilized a sample of undergraduate students in order to increase the level of "experimental

622 control" over the process, as well as the homogeneity of participants, some readers may be

623 concerned that participants lacked autonomy during the reflective process and that, as a

624 result, engagement in the blogging process was mixed. We suggest the engagement levels in

625 the present study were less a case of perceived student autonomy and more a case of some

626 being more committed to learning than others, however, the findings clearly need extension

627 and, if results so indicate, confirmation into "mainstream" coaching. Indeed, Gallimore et al.

628 (2013) make clear there is a need to determine whether guided reflection initiatives can

629 endure beyond concept studies into wide scale implementation in sports coaching. Similarly,

630 there is a need to test whether the reflective skills evidenced during the blogging process

631 endure outside the constrains of a structured and assessed module (Knowles et al., 2006).

632 Indeed, Hobbs (2007) even questions whether or not reflective practice can, in fact, be a

633 required component of a course and still retain validity as genuine reflection. Additionally,

634 there is also a need for better insight into coaches' perception and satisfaction relating to blog

635 use for reflection and social interaction (Kim, 2008). We intend to pursue these lines in both

636 educational and "normal" coach development environments.

637

638

639

640

641

642

643

644

645 
647 Abraham, A., \& Collins, D. (2011). Taking the next step: Ways forward for coaching science. 648 Quest, 63, 366-384.

Billet, S., \& Somerville, M. (2004). Transformations at work: Identity and learning. Studies in Continuing Education, 26(2), 309-326.

Black, P. E., \& Plowright, D. (2010). A multi-dimensional model of reflective learning for professional development. Reflective Practice, 11(2), 245-259.

Boud, D., \& Walker, D. (1998). Promoting reflection in professional courses: The challenge of context. Studies in Higher Education, 23(2), 191-206.

Boulton, H., \& Hramiak, A. (2012). E-flection: The development of reflective communities of learning for trainee teachers through the use of shared online web logs. Reflective Practice, 13(4), 503-515.

Bowes, I., \& Jones, R. L. (2006). Working at the edge of chaos: Understanding coaching as a complex, interpersonal system. The Sport Psychologist, 20, 235-245.

Bruster, B., \& Peterson, B. (2013). Using critical incidents in teaching to promote reflective 661 practice. Reflective Practice, 14(2), 170-182.

Cassidy, T., Potrac, P., \& McKenzie, A. (2006). Evaluating and reflecting upon a coach education initiative: The CoDe of rugby. The Sport Psychologist, 20, 145-161.

664 Chan, K. K., \& Ridgway, J. (2006). Students' perception of using blogs as a tool for reflection and communication. Retrieved from http://www.dur.ac.uk/resources/smart.centre/Publications/ALT-CEdinburghCHAN.doc during internship. Computers \& Education, 58(3), 989-1000.

669 Churchill, D. (2009). Educational applications of Web 2.0: Using blogs to support teaching 670 and learning. British Journal of Educational Technology, 40(1), 179-183. 
671 Cold, S. J. (2006). Using really simple syndication (RSS) to enhance student research. ACM SIGITE Newsletter, 3(1), 6-9.

673 Collins, D., Abraham, A., \& Collins, R. (2012). On vampires and wolves: Exposing and 674 exploring reasons for the differential impact of coach education. International Journal 675 of Sport Psychology, 43(3), 255-271.

676 Cropley, B., \& Hanton, S. (2011). The role of reflective practice in applied sport psychology: Contemporary issues for professional practice. In S. Hanton \& S. D. Mellalieu (Eds.), Professional practice in sport psychology: A review (pp. 307-336). London: Routledge.

679 Cropley, B., Miles, A., Hanton, S., \& Anderson, A. (2007). Improving the delivery of applied 680 681 sport psychology support through reflective practice. The Sport Psychologist, 21, 475494.

Cropley, B., Miles, A., \& Peel, J. (2012). Reflective practice: Value of, issues, and developments within sports coaching. Leeds: Sports Coach UK.

684 Culver, D., \& Trudel, P. (2006). Cultivating coaches' communities of practice: Developing 685 the potential for learning through interactions. In R. L. Jones (Ed.), The sports coach as educator: Re-conceptualising sports coaching (pp. 97-112). London: Routledge.

Culver, D., Trudel, P., \& Werthner, P. (2009). A sport leader's attempt to foster a coaches' community of practice. International Journal of Sports Science and Coaching, 4, 365-

690 Cushion, C. (2006). Mentoring: Harnessing the power of experience. In R. Jones (Ed.), The sports coach as educator: Reconceptualising sports coaching (pp. 128-144). London: Routledge.

693 Cushion, C. J., Armour, K. M., \& Jones, R. L. (2003). Coach education and continuing 694 professional development: Experience and learning to coach. Quest, 55, 215-230. 
695 Cushion, C., Nelson, L., Armour, K., Lyle, J., Jones, R., Sandford, R., \& O’Callaghan, C. (2010). Coach learning and development: A review of literature. Leeds: Sports Coach

697 UK.

Day, C. (1993). Reflection: A necessary but not sufficient condition for professional development. British Educational Research Journal, 19, 83-93.

Dixon, M., Lee, S., \& Ghaye, T. (2013). Reflective practices for better sports coaches and coach education: Shifting from a pedagogy of scarcity to abundance in the run-up to Rio 2016. Reflective Practice, 14(5), 585-599.

Dooly, M. (2008). Constructing knowledge together. In M. Dooly (Ed.), Telecollaborative language learning: a guidebook to moderating intercultural collaboration online (pp. 21-45). Bern: Peter Lang.

Downes, S. (2004). Educational blogging. Educause Review, 39(5), 14-26.

Duffy, P., \& Bruns, A. (2006). The use of blogs, wikis and RSS in education: A conversation of possibilities. Proceedings of the Online Learning and Teaching Conference 2006. Brisbane: Queensland University of Technology.

Erickson, K., M. W. Bruner, D. J. Macdonald, \& Côté, J. (2008). Gaining insight into actual and preferred sources of coaching knowledge. International Journal of Sports Science and Coaching, 3(4), 527-538.

713 Fernsten, I., \& Fernsten, J. (2005). Portfolio assessment and reflection: Enhancing learning through effective practice. Reflective Practice, 6(2), 303-309.

715 Freeman, W., \& Brett, C. (2012). Prompting authentic blogging practice in an online graduate course. Computers \& Education, 59, 1032-1041.

717 Galipeau, J., \& Trudel, P. (2006). Athlete learning in a community of practice. Is there a role for the coach? In R. Jones (Ed.), The sports coach as educator: Re-conceptualising sports coaching (pp. 76-94). London: Routledge. 
720 Gallimore, R., Gilbert, W., \& Nater, S. (2013). Reflective practice and ongoing learning: A coach's 10-year journey. Reflective Practice, i-first, 1-21.

722 Garrison, D., \& Akyol, Z. (2009). Role of instructional technology in the transformation of higher education. Journal of Computing in Higher Education, 21(1), 19-30.

724 Gelter, H. (2003). Why is reflective thinking uncommon? Reflective Practice, 4(3), 337-344.

725 Ghaye, T., \& Ghaye, K. (1998). Teaching \& learning through critical reflective practice. London: David Fulton Publishers.

727 Gibbs G. (1988). Learning by doing: A guide to teaching and learning methods. Oxford $728 \quad$ Further Education Unit: Oxford.

729 Gilbert, W., Gallimore, R., \& Trudel, P. (2009). A learning community approach to coach 730 development in youth sport. Journal of Coaching Education, 2(2), 1-21.

731 Gilbert, W. D., \& Trudel, P. (2001). Learning to coach through experience: Reflection in model youth sport coaches. Journal of Teaching in Physical Education, 21, 16-34.

733 Gilbert, W., \& Trudel, P. (2004). Role of the coach: How model youth team sport coaches 734 frame their roles. The Sport Psychologist, 18, 21-43.

735 Gilbert, W., \& Trudel, P. (2005). Learning to coach through experience: Conditions that 736 influence reflection. Physical Educator, 62(1), 32-43.

737 Gilbert, W., \& Trudel, P. (2006). The coach as a reflective practitioner. In R. L. Jones (Ed.), 738 The sports coach as educator: Re-conceptualising sports coaching (pp. 113-127). 739 London: Routledge.

740 Gilbert, W., \& Trudel, P. (2013). The role of deliberate practice in becoming an expert coach: 741 Part 2 - Reflection. Olympic Coach Magazine, 24, 35-44.

742 Godwin-Jones, B. (2003). Emerging technologies: Blogs and wikis: Environments for on-line $743 \quad$ collaboration. Language Learning \& Technology, 7(2), 12-16. 
744 Halic, O., Lee, D., Paulus, T., \& Spence, M. (2010). To blog or not to blog: Student

745

746

747

748

749

750

751

752

753

754

755

756

757

758

759

760

761

762

763

764

765

766

767 perceptions of blog effectiveness for learning in a college-level course. Internet and Higher Education, 13, 206-213.

Hall, K. D. (2008). Discussion forum versus learning blogs: A comparison of student understanding, student interaction, and social presence. (Doctoral dissertation). Retrieved from Texas Tech University Libraries. (http://hdl.handle.net/2346/11878)

Hara, N., \& Hew, K. F. (2007). Knowledge-sharing in an online community of healthcare professionals. Information Technology \& People, 20(3), 235-261.

Hatton, N., \& Smith, D. (1995). Reflection in teacher education: Towards definition and implementation. Teaching and Teacher Education, 11(1), 22-49.

Hobbs, V. (2007). Faking it or hating it: Can reflective practice be forced? Reflective Practice, 8(3), 405-417.

Holt, N., \& Strean, W. (2001). Reflecting on initiating sport psychology consultation: A selfnarrative of neophyte practice. The Sport Psychologist, 15, 188-204.

Hrastinski, S. (2009). A theory of online learning as online participation. Computers \& Education, 52, 78-82.

Irwin, G., Hanton, S., \& Kerwin, D. (2004). Reflective practice and the origins of elite coaching knowledge. Reflective Practice, 5, 426-442.

Jarvis, P., Holford, J., \& Griffin, C. (2005). The theory and practice of learning (2nd ed.). London: RoutledgeFalmer.

Jones, R. L., Armour, K. M., \& Potrac, P. (2002). Understanding the coaching process: A framework for social analysis. Quest, 54, 34-48.

Jones, R. L., \& Turner, P. (2006). Teaching coaches to coach holistically: Can problem-based learning (PBL) help? Physical Education and Sport Pedagogy, 11, 181-202. 
768 Kang, I., Bonk, C. J., \& Kim, M-C. (2011). A case study of blog-based learning in Korea: Technology becomes pedagogy. Internet and Higher Education, 14(4), 227-235.

770

Killeavy, M., \& Moloney, A. (2010). Reflection in a social space: Can blogging support reflective practice for beginner teachers. Teaching and Teacher Education, 26, 10701076.

Kim, H. N. (2008). The phenomenon of blogs and theoretical model of blog use in educational contexts. Computers \& Education, 51(3), 1342-1352.

Knowles, Z., Borrie, A., \& Telfer, H. (2005). Towards the reflective sports coach: Issues of context, education and application. Ergonomics, 48, 1711-1720.

Knowles, Z., Gilbourne, D., Borrie, A., \& Neville, A. (2001). Developing the reflective sports coach: A study exploring the processes of reflection within a higher education coaching programme. Reflective Practice, 2, 185-207.

Knowles, Z., Tyler, G., Gilbourne, D., \& Eubank, M. (2006). Reflecting on reflection: Exploring the practice of sports coaching graduates. Reflective Practice, 7, 163-179.

Kol, S., \& Schcolnik, M. (2008). Asynchronous forums in EAP: Assessment issues. Language Learning \& Technology 12(2), 49-70.

Krane, V., Andersen, M. B., \& Strean, W. B. (1997). Issues of qualitative research methods and presentation. Journal of Sport and Exercise Psychology, 19, 213-218.

Larrivee, B. (2008). Development of a tool to assess teacher's level of reflective practice. Reflective Practice 9(3), 341-360.

Lemyre, F., Trudel, P., \& Durand-Bush, N. (2007). How youth sport coaches learn to coach. The Sport Psychologist, 21, 191-209.

Lucas, P., \& Fleming, J. (2012). Reflection in sport and recreation cooperative education: Journals or blogs? Asia-Pacific Journal of Cooperative Education, 13(1), 55-64. 
792 Lyle, J. (2002). Sports coaching concepts: A framework for coaches' behaviour. London: $793 \quad$ Routledge.

794 Lyle, J., \& Cushion, C. (Eds.). (2010). Sports coaching: Professionalisation and practice. 795 Edinburgh: Churchill Livingstone Elsevier.

796 Makri, K., \& Kynigos, C. (2007). The role of blogs in studying the discourse and social 797 practices of mathematics teachers. Educational Technology \& Society, 10(1), 73-84.

798 Mallett, C., Rossi, T., \& Tinning, R. (2007). Report to the AFL: Coaching knowledge, learning and mentoring in the AFL. St Lucia, Australia: The University of Queensland.

Manouchehri, A. (2002). Developing teaching knowledge through peer discourse. Teaching and Teacher Education, 18, 715-737.

Mezirow, J. (1990). How critical reflection triggers transformative learning. In J. Mezirow (Ed.), Fostering critical reflection in adulthood: a guide to transformative and emancipatory learning (pp. 1-20). San Francisco: Jossey-Bass.

Moon, J. (2006). Learning journals: A handbook for reflective practice and professional development (2nd ed.). New York: Routledge.

Morgan, K., Jones, R. L., Gilbourne, D., \& Llewellyn, D. (2013). Innovative pedagogies in 808 coach education. In P. Potrac, W. Gilbert \& J. Denison (Eds.), The Routledge handbook of sports coaching (pp. 486-496). London: Routledge.

Nash, C., \& Sproule, J. (2009). Career development of expert coaches. International Journal of Sports Science and Coaching, 4(1), 121-138.

812 Nelson, L. J., Cushion, C. J., \& Potrac, P. (2006). Formal, nonformal and informal coach 813 learning: A holistic conceptualization. International Journal of Sports Science and $814 \quad$ Coaching, 1, 247-259.

815 Otienoh, R. (2009). Reflective practice: The challenge of journal writing. Reflective Practice, 816 10, 477-489. 
817 Parkes, K., \& Kajder, S. (2010). Eliciting and assessing reflective practice: A case study in Web 2.0 technologies. International Journal of Teaching and Learning in Higher Education, 22(2), 218-228.

Peel, J., Cropley, B., Hanton, S., \& Fleming, S. (2013). Learning through reflection: Values, conflicts, and role interactions of a youth sport coach. Reflective Practice, 14(6), 729742.

Piggott, D. (2013). The open society and coach education: A philosophical agenda for policy reform and future sociological research. Physical Education and Sport Pedagogy, $i$ first, 1-16.

Pinkman, K. (2005). Using blogs in the foreign classroom: Encouraging learner independence. JALT CALL Journal, 1(1), 12-24.

Poom-Valickis, K., \& Mathews, S. (2013). Reflecting others and own practice: An analysis of novice teachers' reflection skills. Reflective Practice, 14(3), 420-434.

Reingold, R., Rimor, R., \& Kalay, A. (2008). Instructor's scaffolding in support of student's meta-cognition through a teacher education online course: A case study. Journal of Interactive Online Learning, 7(2), 139-151.

Robertson, J. (2011). The educational affordances of blogs for self-directed learning. Computers \& Education, 57(2), 1628-1644.

835 Romiszowski, A., \& Mason, R. (2004). Computer-mediated communication. In D. H. Jonassen (Ed.), Handbook of research for educational communications and technology

838 Rourke, L., \& Anderson, T. (2004). Validity in quantitative content analysis. Educational Technology Research and Development, 52(1), 5-18.

840 Saylor, C. R. (1990). Reflection and professional education: Art, science, and competency. 
842 Sen, B., \& Ford, N. (2009). Developing reflective practice in LIS education: The SEAchange model of reflection. Education for Information, 27, 181-195.

844 Sharma, P., \& Xie, Y. (2008). Student experiences of using weblogs: An exploratory study. Journal of Asynchronous Learning Networks, 12(3-4), 137-156.

846 Smith, A., \& Jack, K. (2005). Reflective practice: A meaningful task for students. Nursing Standard, 19, 33-37.

848 Sports Coach UK (2012a). The UKCC level 1-3 support guide (2 ${ }^{\text {nd }}$ ed.). Leeds, UK: Coachwise Ltd.

Sports Coach UK. (2012b). Coach tracking study: A four-year study of coaching in the UK. Leeds: Sports Coach UK.

Stiler, G. M., \& Philleo, T. (2003). Blogging and blogspots: An alternative format for encouraging reflective practice among preservice teachers. Education, 123(4), 789-797.

Stephenson, B., \& Jowett, S. (2009). Factors that influence the development of English youth soccer coaches. International Journal of Coaching Science, 3(1), 3-16.

856 Stoszkowski, J., \& Collins, D. (2012). Communities of practice, social learning and networks: Exploiting the social side of coach development. Sport, Education and Society, $i$-first, 1-16.

Tan, A. (2006). Does scaffolded blogging promote preservice teacher reflection? Examining the relationships between learning tool and scaffolding in a blended learning environment. (Doctoral dissertation). Retrieved from IUScholarWORKS. (http://hdl.handle.net/2022/7774)

863 Thompson, N., \& Pascal, J. (2012). Developing critically reflective practice. Reflective 864 Practice, 13(2), 311-325.

865 Thompson, S., \& Thompson, N. (2008). The critically reflective practitioner. Basingstoke: 
867 Top, E., Yukselturk, E., \& Inan, F. A. (2010). Reconsidering usage of blogging in preservice 868 teacher education courses. Internet and Higher Education, 13(4), 214-217.

869

Trudel, P., \& Gilbert, W. (2004). Communities of practice as an approach to foster ice hockey coach development. Safety in Ice Hockey, 4, 167-79.

Vygotsky, L. (1978). Mind in society: The development of higher psychological processes. London: Harvard University Press.

Wenger, E. (1998). Communities of practice: Learning, meaning, and identity. Cambridge: Cambridge University Press.

Wenger, E., McDermott, R. \& Snyder, W. M. (2002). Cultivating communities of practice. Boston: Harvard Business School Press.

Werthner, P., \& Trudel, P. (2006). A new theoretical perspective for understanding how coaches learn to coach. The Sport Psychologist, 20, 198-212.

Whipp, J. L. (2003). Scaffolding critical reflection in online discussions: Helping prospective teachers think deeply about field experiences in urban schools. Journal of Teacher Education, 54(4), 321-333.

Whitcomb, M. (2003). The information technology age is dawning for medical education. 883 Academic Medicine, 78(3), 247-8.

884

Wolf, K. (2010). Bridging the distance: The use of blogs as a reflective learning tool for 885 placement students. Higher Education Research and Development, 2(5), 589-602.

886 Wright, T., Trudel, P., \& Culver, D. (2007). Learning how to coach: the different learning 887 situations reported by youth ice hockey coaches. Physical Education and Sport 888 Pedagogy, 12(2), 127-144. 
Table 1

Number and Quality of Blog Posts According to Hatton and Smith's (1995) Framework

\begin{tabular}{|c|c|c|c|c|c|c|c|c|c|}
\hline \multirow{2}{*}{$\begin{array}{c}\text { Coach } \\
1\end{array}$} & \multirow{2}{*}{$\begin{array}{l}\text { Sport } \\
\text { Soccer }\end{array}$} & \multicolumn{2}{|c|}{$\begin{array}{c}\text { Semester } 1 \\
\text { DiaR + CriR / } \\
\text { Total }\end{array}$} & \multicolumn{2}{|c|}{$\begin{array}{c}\text { Semester } 2 \\
\text { DiaR + CriR / } \\
\text { Total }\end{array}$} & \multicolumn{2}{|c|}{$\begin{array}{c}\text { Total }(\mathrm{S} 1+\mathrm{S} 2) \\
\text { DiaR + CriR } / \\
\text { Total }\end{array}$} & \multirow{2}{*}{$\begin{array}{c}\text { Increase number } \\
\text { of posts } \\
\text { (Total S2 - S1) }\end{array}$} & \multirow{2}{*}{$\begin{array}{c}\begin{array}{c}\text { Increase quality } \\
\text { of reflection } \\
(\% \mathrm{~S} 2-\mathrm{S} 1)\end{array} \\
\text { Yes }\end{array}$} \\
\hline & & $6 / 13$ & $46 \%$ & $4 / 5$ & $80 \%$ & $10 / 18$ & $56 \%$ & & \\
\hline 2 & Soccer & $1 / 7$ & $14 \%$ & $4 / 10$ & $40 \%$ & $5 / 17$ & $29 \%$ & Yes & Yes \\
\hline 3 & Soccer & $0 / 6$ & $0 \%$ & $2 / 13$ & $15 \%$ & $2 / 19$ & $11 \%$ & Yes & Yes \\
\hline 4 & Cricket & $1 / 17$ & $6 \%$ & $4 / 14$ & $29 \%$ & $5 / 31$ & $16 \%$ & No & Yes \\
\hline 5 & Multisport & $0 / 6$ & $0 \%$ & $1 / 9$ & $11 \%$ & $1 / 15$ & $7 \%$ & Yes & Yes \\
\hline 6 & Multisport & $4 / 9$ & $44 \%$ & $6 / 8$ & $75 \%$ & $10 / 17$ & $59 \%$ & No & Yes \\
\hline 7 & Multisport & $2 / 7$ & $29 \%$ & $6 / 10$ & $60 \%$ & $8 / 17$ & $47 \%$ & Yes & Yes \\
\hline 8 & Multisport & $0 / 9$ & $0 \%$ & $4 / 6$ & $67 \%$ & $4 / 15$ & $27 \%$ & No & Yes \\
\hline 9 & Tennis & $3 / 6$ & $50 \%$ & $9 / 14$ & $64 \%$ & $12 / 20$ & $60 \%$ & Yes & Yes \\
\hline 10 & Soccer & $0 / 7$ & $0 \%$ & $1 / 6$ & $17 \%$ & $1 / 13$ & $8 \%$ & No & Yes \\
\hline 11 & Gymnastics & $0 / 9$ & $0 \%$ & $2 / 8$ & $25 \%$ & $2 / 17$ & $12 \%$ & No & Yes \\
\hline 12 & Cricket & $1 / 7$ & $14 \%$ & $6 / 8$ & $75 \%$ & $7 / 15$ & $47 \%$ & Yes & Yes \\
\hline 13 & Tennis & $4 / 10$ & $40 \%$ & $10 / 11$ & $91 \%$ & $14 / 21$ & $67 \%$ & Yes & Yes \\
\hline 14 & Soccer & $3 / 8$ & $38 \%$ & $5 / 8$ & $63 \%$ & $8 / 16$ & $50 \%$ & No & Yes \\
\hline
\end{tabular}




\begin{tabular}{|c|c|c|c|c|c|c|c|c|c|}
\hline 15 & Cricket & $2 / 8$ & $25 \%$ & $1 / 7$ & $14 \%$ & $3 / 15$ & $20 \%$ & No & No \\
\hline 16 & Soccer & $5 / 10$ & $50 \%$ & $6 / 7$ & $86 \%$ & $11 / 17$ & $65 \%$ & No & Yes \\
\hline 17 & Soccer & $0 / 5$ & $0 \%$ & $1 / 10$ & $10 \%$ & $1 / 15$ & $7 \%$ & Yes & Yes \\
\hline 18 & Soccer & $1 / 7$ & $14 \%$ & $2 / 8$ & $25 \%$ & $3 / 15$ & $20 \%$ & Yes & Yes \\
\hline 19 & Soccer & $0 / 7$ & $0 \%$ & $2 / 8$ & $25 \%$ & $2 / 15$ & $13 \%$ & Yes & Yes \\
\hline 20 & Soccer & $0 / 6$ & $0 \%$ & $1 / 8$ & $13 \%$ & $1 / 14$ & $7 \%$ & Yes & Yes \\
\hline 21 & Soccer & $1 / 7$ & $14 \%$ & $0 / 7$ & $0 \%$ & $1 / 14$ & $7 \%$ & No & No \\
\hline 22 & Soccer & $1 / 7$ & $14 \%$ & $4 / 7$ & $57 \%$ & $5 / 14$ & $36 \%$ & No & Yes \\
\hline 23 & Basketball & $15 / 16$ & $94 \%$ & $9 / 10$ & $90 \%$ & $24 / 26$ & $92 \%$ & No & No \\
\hline 24 & Soccer & $0 / 6$ & $0 \%$ & $1 / 4$ & $25 \%$ & $1 / 10$ & $10 \%$ & No & Yes \\
\hline 25 & Field hockey & $0 / 5$ & $0 \%$ & $2 / 11$ & $18 \%$ & $2 / 16$ & $13 \%$ & Yes & Yes \\
\hline \multirow[t]{2}{*}{26} & Field hockey & $0 / 13$ & $0 \%$ & $2 / 13$ & $15 \%$ & $2 / 26$ & $8 \%$ & No & Yes \\
\hline & TOTAL & $50 / 218$ & $23 \%$ & $95 / 230$ & $41 \%$ & $145 / 448$ & $32 \%$ & No & Yes \\
\hline
\end{tabular}

Note DiaR $=$ Dialogic reflection; CriR $=$ Critical reflection; $\mathrm{S} 1=$ Semester $1 ; \mathrm{S} 2=$ Semester 2 
Table 2

Topic Categories and Number of Coaches' Blog Posts

\begin{tabular}{lccc}
\hline Topic Category & Semester 1 & Semester 2 & Total Number \\
\hline 1. Theories of coaching & $88(40.55 \%)$ & $119(51.52 \%)$ & $207(46.21 \%)$ \\
2. Own coaching practice & $143(65.90 \%)$ & $147(63.64 \%)$ & $290(64.73 \%)$ \\
3. Others' coaching practice & $28(12.90 \%)$ & $30(12.99 \%)$ & $58(12.95 \%)$ \\
4. Self-awareness & $96(44.24 \%)$ & $112(48.48 \%)$ & $208(46.43 \%)$ \\
5. Blogging & $19(8.76 \%)$ & $17(7.35 \%)$ & $36(8.03 \%)$ \\
5a. The use of the blog & $12(5.53 \%)$ & $12(5.19 \%)$ & $24(5.35 \%)$ \\
5b. Interacting with others online & $7(3.23 \%)$ & $5(2.16 \%)$ & $12(2.68 \%)$ \\
\hline
\end{tabular}

Note. Total percentage exceeds $100 \%$ as a single blog post $(n=448)$ could fit into more than one category. 
Table 3

Coaches' Blog Posts According to Hatton and Smith's (1995) Framework

\begin{tabular}{llll}
\hline Level of reflection & Semester 1 & Semester 2 & Total Number \\
\hline Descriptive writing & $35(16.13 \%)$ & $15(6.49 \%)$ & $50(11.16 \%)$ \\
Descriptive reflection & $133(61.29 \%)$ & $120(51.95 \%)$ & $253(56.47 \%)$ \\
Dialogic reflection & $48(22.12 \%)$ & $86(37.23 \%)$ & $134(29.91 \%)$ \\
Critical reflection & $2(0.92 \%)$ & $9(3.90 \%)$ & $11(2.45 \%)$ \\
\hline
\end{tabular}

